EI.JEST

\title{
A NUMERICAL/EXPERIMENTAL STUDY OF A MULTI-STAGE CENTRIFUGAL COMPRESSOR *
}

\author{
Nabil H. Mostafa, Ahmed F. Abdul-gawad, and Mohamed S. Emeara** \\ Mechanical Power Engineering Department, Zagazig University, Egypt.
}

\begin{abstract}
Both computational and experimental investigations were utilized to study the flow behavior inside the four-stage centrifugal compressor. Computational study was carried out by the commercial code "CFD-RC". Experimental work was accomplished by the use of a data acquisition system, advanced sensors and "LabView" interface software. Comparisons between computational and experimental outputs were performed.

The computational code was validated experimentally and numerically. Compressor map was drawn numerically and experimentally. Surge was unsteadily simulated. Surge predicted at mass flow equal to $0.0093 \mathrm{~kg} / \mathrm{s}$ for $12,000 \mathrm{rpm}$ with full-domain solution. Using the parallel computational technology, by "HPC" program, is recommended for future work.
\end{abstract}

KEY WORDS: Surge Simulation, Multi-stage, Centrifugal Compressor, Unsteady, full-domain.

\section{UNE ETUDE NUMERIQUE / EXPERIMENTALE D'UN COMPRESSEUR MULTI-ETAGE CENTRIFUGE}

\section{RÉSUMÉ}

Les deux enquêtes informatiques et expérimentales ont été utilisées pour étudier le comportement de l'écoulement à l'intérieur du compresseur centrifuge en quatre étapes. Étude computationnelle a été réalisée par le code du commerce "CFD-RC". Le travail expérimental a été réalisé par l'utilisation d'un système d'acquisition de données, capteurs et de logiciels avancés "LabView" interface. Les comparaisons entre les sorties numériques et expérimentales ont été effectuées.

Le code de calcul a été validé expérimentalement et numériquement. Compresseur carte a été dessinée numériquement et expérimentalement. Surge a été chancelant simulées. Surgé prédit au débit massique égal à $0.0093 \mathrm{~kg} / \mathrm{s}$ pour $12000 \mathrm{rpm}$ avec plein de domaine solution. Utilisation de la technologie parallèle de calcul, par «HPC» du programme, est recommandée pour les travaux futurs.

MOTS CLÉS: Simulation de surtension, multi-stade, un compresseur centrifuge, instable, plein de domaine.

* Received: 21/11/2010, accepted: 22/5/2011 (Original Paper)

** Contact author(m_emeara@yahoo.com, 0149067505) 


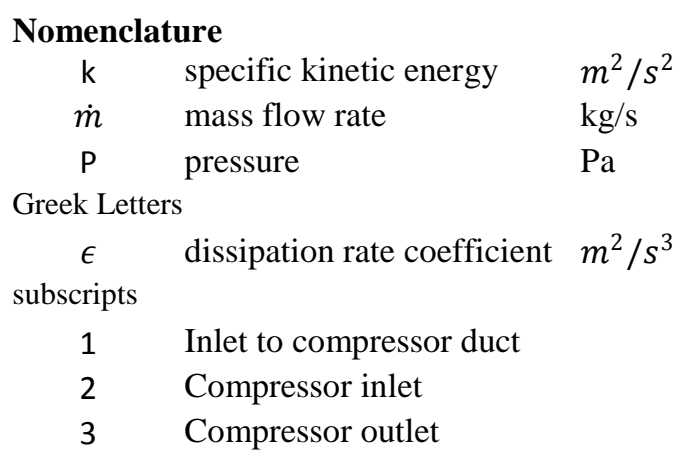

$\begin{array}{ll}\text { Abbreviations } \\ \text { 3D } & \text { three dimension } \\ \text { A/D } & \text { analog to digital } \\ \text { CFD-RC } & \begin{array}{l}\text { Computational Fluid Dynamics } \\ \text { Research Cooperation, name of a } \\ \text { commercial code }\end{array} \\ & \begin{array}{l}\text { fast Fourier transformation } \\ \text { install and calibrate }\end{array} \\ \text { FFT } & \begin{array}{l}\text { Micro Propulsion Group } \\ \text { InstaCall } \\ \text { MPG }\end{array} \\ \text { NPT } & \begin{array}{l}\text { negative pressure transducer } \\ \text { positive pressure transducer }\end{array} \\ \text { PPT } & \begin{array}{l}\text { revolutions per minute } \\ \text { rpm }\end{array} \\ \text { UDM } & \begin{array}{l}\text { uniform design method } \\ \text { C }\end{array} \\ \end{array}$

\section{INTRODUCTION}

Centrifugal compressors are identified as radial turbomachines. This type of compressor is composed of three main elements, namely, the rotating part or impeller, and stationary parts; diffuser and manifold. An important part up stream of the impeller is the inducer duct.

Air is sucked into the impeller eye and whirled round at high speed by the vanes on the impeller disc. The normal practice is to design the compressor so that about half the pressure rise occurs in the impeller and half in the diffuser, Cohen et al., [1].

Large variations in pressure contours are not observed when crossing the boundary between the two major components, but noticeable gradients are present at the diffuser outlet because of the sudden increase in width at the volute inlet. Still heavier distortions in the pressure are present at the volute tongue because of the large incidence, creating a separation like flow on the suction side of the tongue, Rangwala, [5].

\subsection{Previous Work}

Niazi et. al., [4] employed a sectordomain (or passage) between two successive blades) in the impeller for numerical calculations for the flow in an impeller of single-stage centrifugal compressor. $\mathrm{He}$ generated a grid of 400,000 nodes; next he increased the number of nodes till 1.8 million nodes in a mesh sensitivity analysis. Code validation with achieved via comparison with experimental data. He was able to simulate surge and studied surge control by air-injection. He also examined other parameters such as velocity and total pressure.

Tijl, [7] studied experimentally surge avoidance. Transient simulation of flow parameters was accomplished. He obtained a qualitative evaluation of the behavior of the modeled compressor.

$\mathrm{Xu}$ and Muller, [8] presented a detailed flow simulation in the volute of a singlestage centrifugal compressor. Their computational domain had 782,000 nodes. The "Frozen-rotor" method is used at interfaces between rotating and stationary elements. They considered a full-domain flow study and plotted the pressure distribution of the volute.

Yutaka et al., [10] carried out a numerical and experimental study of the centrifugal-compressor noise affected by the flow in the tapered diffuser. Experimentally, they presented advanced experimental setup. Numerically, 3D steady model was used to simulate flow. The numerical model utilized a full-domain mesh (single-stage) and a sliding mesh method.

Ling et al., [2] simulated a small centrifugal compressor undertaken at the MPG and KJ66 gas turbine design. They studied improving the efficiency of the compressor by increasing the impeller diameter from $66 \mathrm{~mm}$ to $71 \mathrm{~mm}$. They found that the performance of the new design is better than the old one within a certain operating ranges. 
Xinwei et al., [9] An efficient optimization approach to centrifugal impeller blades is developed and applied to the design of a 3D impeller using; UDM, CFD, regression analysis method, and genetic algorithm. Global optimization of the approximate function is obtained by genetic algorithms. Taking maximum isentropic efficiency as objective function, this optimization approach has been applied to the optimum design of a certain centrifugal compressor blades. The results, compared with those of the original one, show that isentropic efficiency of the optimized impeller has been improved which indicates the effectiveness of the proposed optimization approach such as CFD, structural dynamics, and thermal analysis combined with the emergence of improved optimization algorithms makes it possible to perform blade shape automatic optimization process.

Tang et al., [6] studied numerically a 3D impeller and vaneless diffuser of a small centrifugal compressor. The influence of impeller tip clearance on the flow field of the impeller was investigated. Then, a new partially shrouded impeller was designed. They used a sector-domain and 110,000 grid points. Numerical results show that the secondary flow region becomes smaller at the exit of the impeller. Better performance is achieved in comparison with the unshrouded impeller.

The previous works supported the present research as will be mentioned. Comparison between these works is performed in Table 1.

Table 1 Comparison between some previous works.

\begin{tabular}{|c|c|c|c|}
\hline & $\mathrm{Xu}$ & Stein & Yutaka \\
\hline solution dim. & $3 \mathrm{D}$ & $3 \mathrm{D}$ & $3 \mathrm{D}$ \\
\hline CFD domain & full & sector & full \\
\hline stages no. & single & single & single \\
\hline no. of nodes & 782,000 & 400,000 & $1,425,000$ \\
\hline rotating model & Frozen-rotor & no rotation & Sliding-mesh \\
\hline
\end{tabular}

\subsection{Compressor Surge}

Surge is an axisymmetrical oscillation of the flow through the compressor, and is characterized by a limit cycle in the compressor characteristic. An example of such characteristic is shown as $\mathrm{S}$-shape curve. The characteristic shows the pressure rise over the compressor as a function of the mass flow rate. The surge severity can be classified in two levels: mild and deep surge Mostafa, [3].

\subsection{Case Study}

A four-stage centrifugal compressor was used. The compressor design point is at $12,000 \mathrm{rpm}, 0.022 \mathrm{~kg} / \mathrm{s}$, and 1.25 static pressure ratio. The compressor is manufactured by Armfeild Company and its serial number is C1-MKII. Experimental work was done in Measurements Lab., Mechanical Power Dept., Faculty of Engineering, Zagazig University.

\section{NUMERICAL ANALYSIS}

In the numerical simulation, a 3D steady and un-steady flow field is calculated. Steady flow was in order to draw a numerical compressor map. Un-steady was in order to investigate the surge. "CFD-RC" code is used in CFD study.

\subsection{Governing Equations}

The simulations are carried out by solving governing equations of a continuity equation, a 3D unsteady compressible Navier-Stokes equation, an energy equation and an equation of the state of an ideal gas. The $k-\epsilon$ turbulence model was used in the simulation.

\section{Continuity equation:}

$$
\frac{\partial \rho}{\partial t}+\frac{\partial}{\partial x_{i}}\left(\rho V_{i}\right)=0
$$

where:

$V_{i}:$ the velocity in the $i^{\text {th }}$ direction

$x_{i}:$ the coordinate in the $i^{\text {th }}$

direction

$\rho:$ : is the air density.

$i \quad: \quad$ a tensor indicating $1,2,3$. 
3D Navier-stokes equation:

$$
\frac{\partial\left(\rho V_{i}\right)}{\partial t}+\frac{\partial}{\partial x_{j}}\left(\rho V_{i} V_{j}\right)=-\frac{\partial p}{\partial x_{i}}+\frac{\partial \tau_{i j}}{\partial x_{j}}
$$

where $p$ is the static pressure, and $\tau_{i j}$ is the viscous stress tensor given by

$$
\tau_{i j}=\mu\left[\frac{\partial V_{i}}{\partial x_{j}}+\frac{\partial V_{j}}{\partial x_{i}}-\frac{2}{3} \frac{\partial V_{l}}{\partial x_{l}}\right]
$$

where;

$$
\begin{aligned}
& \mu \quad: \quad \text { is the absolute viscosity. } \\
& i, j, l: \begin{array}{l}
\text { are tensor indices indicating } \\
1,2,3 \text {. }
\end{array}
\end{aligned}
$$

\section{Energy equation:}

$\frac{\partial(\rho E)}{\partial t}+\frac{\partial}{\partial x_{i}}\left[V_{i}(\rho E+p)\right]=\frac{\partial}{\partial x_{i}}\left(K \frac{\partial T}{\partial x_{i}}-\sum_{j} h_{j} J_{i}+\left(V_{i} \tau_{i j}\right)\right) h$

where;

$E \quad: \quad$ is the total energy of the air.

$K \quad: \quad$ is the air thermal conductivity. $J_{i} \quad$ is the diffusion flux of $j^{\text {th }}$ species in the
$\quad i^{\text {th }}$ direction.

Turbulence model Equations:

1- Equation of turbulence energy $(k)$ :

$\frac{\partial}{\partial t}(\rho k)+\frac{\partial}{\partial x_{i}}\left(\rho k u_{i}\right)=\frac{\partial}{\partial x_{j}}\left[\left(\mu+\frac{\mu_{t}}{\sigma_{k}}\right) \frac{\partial k}{\partial x_{j}}\right]-\rho \epsilon$

2- Equation of rate of dissipation of turbulence kinetic energy $(\epsilon)$ :

$$
\frac{\partial}{\partial t}(\rho \epsilon)+\frac{\partial}{\partial x_{i}}\left(\rho \epsilon u_{i}\right)=\frac{\partial}{\partial x_{j}}\left[\left(\mu+\frac{\mu_{t}}{\sigma_{\epsilon}}\right) \frac{\partial \epsilon}{\partial x_{j}}\right]+C_{1 \epsilon} \frac{\epsilon}{k} C_{3 \epsilon}-C_{2 \epsilon} \frac{\epsilon^{2}}{k}
$$

The model constants $C_{1 \epsilon}, C_{2 \epsilon}$, $C_{\mu}, \sigma_{k}$, and $\sigma_{\epsilon}$ have the following default values:

$C_{1 \epsilon}=1.44, C_{2 \epsilon}=1.92, C_{\mu}=0.09, \sigma_{k}=$ 1.0, and $\sigma_{\epsilon}=1.3$.

\subsection{Computational Settings}

The computational grid used in the present simulation is illustrated in Figs. 1. The simulation is carried out in the whole region of the impeller, return-bends, and volute.

The blades defined as rotating walls and the "Sliding-Mesh" method used to interface between rotating and fixed zones. General "Interface" is defined between two fixed zones. Rotating modeling is illustrated in Fig. 2.

Structure hexahedral cells are generated in the impeller inlet, impellers, return-bends, and volute zones. The grid system has
449,930 cells (584,900 nodes). Mesh sensitivity is studied till 850,000 nodes. A fine grid is used near the hub of impeller and in return-bends.

Constants of the used turbulence model $(\mathrm{k}-\epsilon)$ are; $\mathrm{k}=0.06 \mathrm{~m}^{2} / \mathrm{s}^{2}, \epsilon=39 \mathrm{~m}^{2} / \mathrm{s}^{3}$. For unsteady simulation, the optimum time step was $1 \times 10^{-4} \mathrm{sec}$.

Initial conditions for velocities were used as approximated zero flow of $1 \mathrm{~m} / \mathrm{s}$. This is only for initial guess and then the code solves to get the correct values. For pressures, the atmospheric values were used as initial guess.

The inlet boundary condition is that the total pressure is constant and equal to atmospheric. The outlet boundary condition is that the back pressure (static pressure) is constant.

A computer 2.2 GB Intel $®$ core TM 2 duo processor and 3 GB RAM was used with a Hard disk of 40 GB. For unsteady (transient) solution, a whole day ( 24 hours) was needed to solve only one time step. For steady solution, about 90 hours needed.

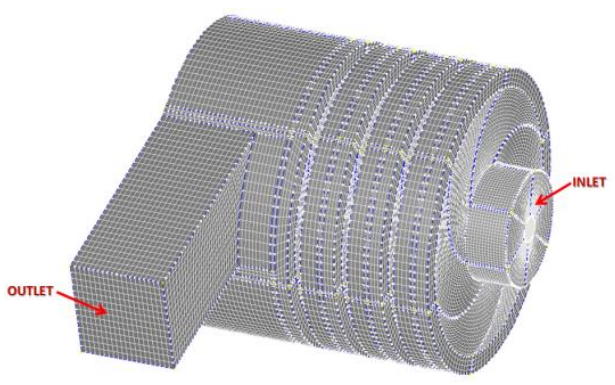

Fig. (1): Computational domain .

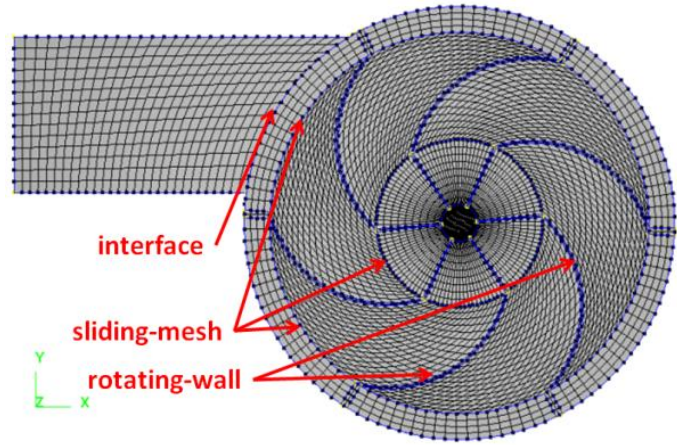

Fig. (2): Rotation Modeling. 


\section{EXPERIMENTAL SETUP}

There are four main parameters needed to draw the compressor map. These four parameters are; 1- rotational speed $\mathrm{N}$ (rpm), 2- mass flow rate $\dot{\mathrm{m}}(\mathrm{kg} / \mathrm{s}), \quad 3$ - pressure ratio $\frac{\mathrm{P}_{3}}{\mathrm{P}_{2}}$ or $\frac{\mathrm{P}_{\mathrm{t} 3}}{\mathrm{P}_{\mathrm{t} 2}}$, and 4- isentropic efficiency $\eta_{\mathrm{C}}$.

Measurements were measured at three points which are; (point 1) which is inlet to compressor duct, and (point 2) which is inlet to the compressor, Fig. (3). Digital instruments are used to make accurate and fast response measurements.

PPT is used to measure +ve pressure which at compressor outlet, point 3 in Fig. (3). NPT is used to measure the compressor suction pressures such as points 1 and 2 , shown in Fig. (3). Sensitive fast response thermocouple was used to acquire the temperature of the measurements at points 1 , 2, and 3. Digital speedometer was used to measure the compressor rotational speed directly.

$\mathrm{A} / \mathrm{D}$ card is used to acquire the output signals from the devices. Its manufacturing company is "Computer Boards" company. The A/D converter is 16 bit, $1 \mathrm{MHz}$ and it is labeled as CIO-DAS1602/16. Its base address is $300 \mathrm{H}$ and it was connected based on a differential method.

"InstaCall" software is used to drive the A/D card with the computer. "LabView" software is used to read the A/D signals and then processing them. Analyzing the output signals of the digital devices are accomplished by FFT technique and "LabView" software.

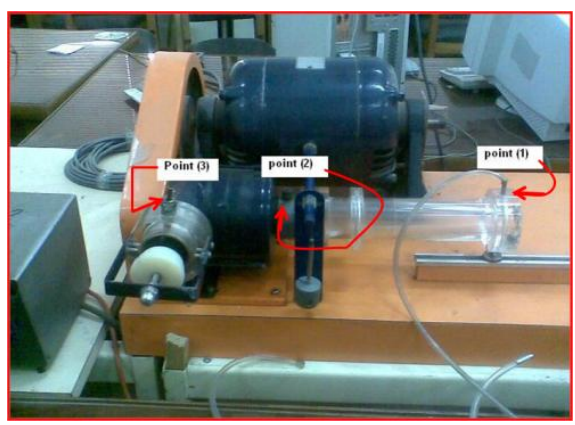

Fig. (3) Experimental Setup.

\section{VALIDATION OF RESULTS}

Computational results were validated by two ways. At first, the numerical map of the present compressor was compared with its experimental map. Secondly, the computed pressure distribution of the present compressor was checked and compared by other published results.

Fig. (4) shows the relation between the static pressure ratio and the mass flow rate at $12 \mathrm{k}, 9 \mathrm{k}$, and $6 \mathrm{k} \mathrm{rpm}$. Comparison between the numerical results and the measured results were performed. The comparison was carried out with respect to the compressor manufacturing data (Armfeild).

Figs. (5)-(7) shows the relation between the static pressure ratio and the mass flow rate at $12 \mathrm{k} \mathrm{rpm}, 9 \mathrm{k} \mathrm{rpm}$, and $6 \mathrm{k} \mathrm{rpm}$, respectively. Comparison between the numerical results and the measured results were performed. The comparison was carried out with respect to the compressor manufacturing data (Armfeild). A comparison between measured and numerical results was performed, Table (2).

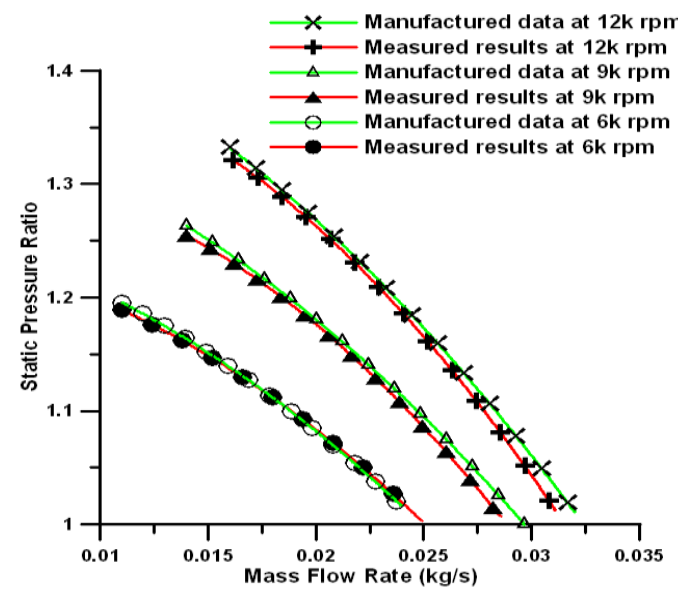

Fig. (4): Comparison of the Measurements with Manufacturer's Data, (Static Pressure Ratio versus Mass Flow Rate for Different Compressor Speeds).

Table (2): Percentage Error Values for Measured and Numerical Results

\begin{tabular}{|c|c|c|c|c|}
\hline \multirow{2}{*}{ rpm } & \multicolumn{2}{|c|}{ measured results } & \multicolumn{2}{c|}{ numerical results } \\
\cline { 2 - 5 } & range & average & range & average \\
\hline $12 \mathrm{k}$ & $0.40 \%-0.50 \%$ & $0.82 \%$ & $0.20 \%-0.90 \%$ & $0.81 \%$ \\
\hline $9 \mathrm{k}$ & $0.44 \%-0.49 \%$ & $0.47 \%$ & $0.7 \%-1.47 \%$ & $1.2 \%$ \\
\hline $6 \mathrm{k}$ & $0.41 \%-0.49 \%$ & $0.45 \%$ & $1.18 \%-1.95 \%$ & $1.75 \%$ \\
\hline
\end{tabular}




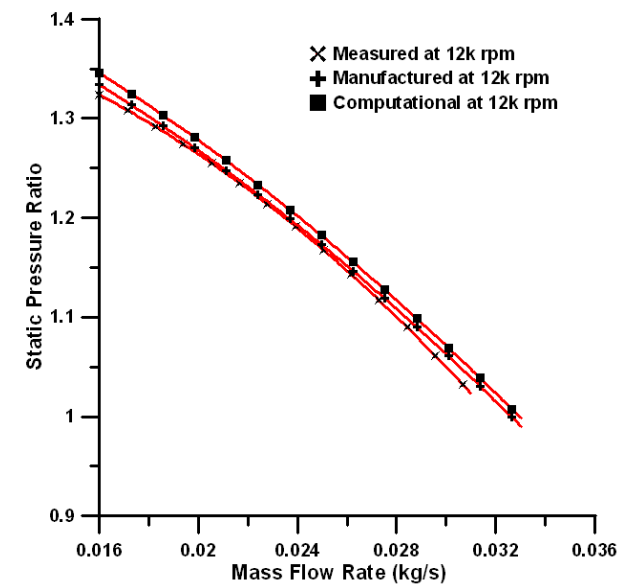

Fig. (5): Comparison of Measurement and Numerical Results with Manufacturer's Data at 12k rpm.

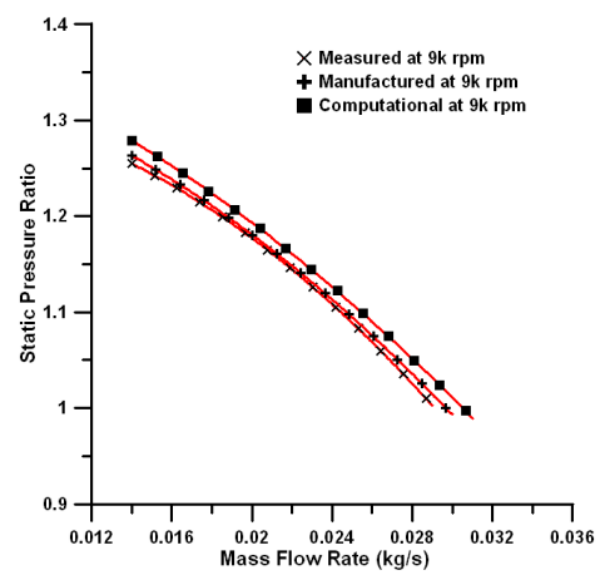

Fig. (6): Comparison of the Measurements and Numerical Results with Manufacturer's Data at 9k rpm.

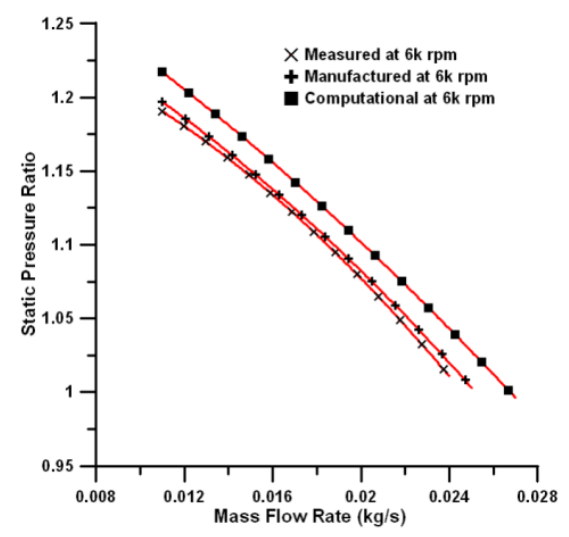

Fig. (7): Comparison of the Measurements and Numerical Results with Manufacturer's Data at 6k rpm.
As the compressor speed $\mathrm{N}$ increases, inlet static pressure $\mathrm{P}_{2}$ decreases and then inlet kinetic energy increases. Thus, the compressor inlet velocity $\mathrm{C}_{2}$ increases. On the other hand, the compressor outlet static pressure $\mathrm{P}_{3}$ increases as the outlet kinetic energy is reduced in the volute. However, the outlet velocity approaches the value of inlet velocity. The outlet velocities coincided with each others for different compressor speeds $\mathrm{N}=6 \mathrm{k}, 9 \mathrm{k}$ and $12 \mathrm{k} \mathrm{rpm}$. This is shown in Fig. (8). Accordingly, the Mach numbers take the same increasing trend as can be seen in Fig. (9).

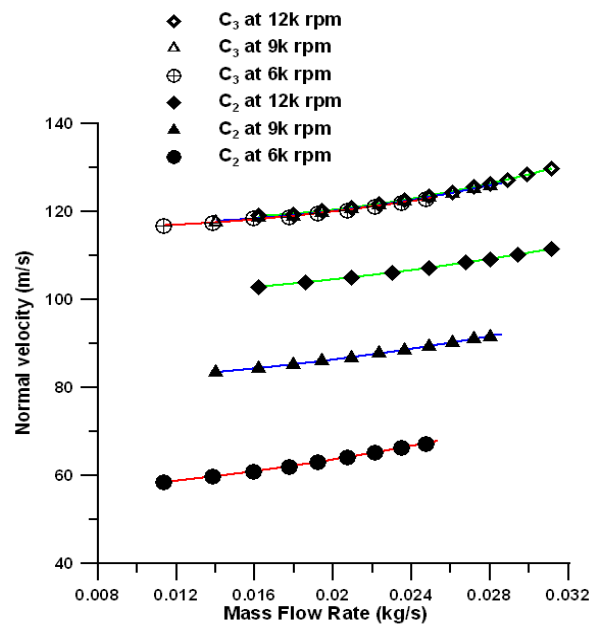

Fig. (8): Measured Absolute Velocities at Compressor Inlet and Outlet vs. Mass Flow Rate for Different Compressor Speeds.

In order to check the CFD solution, the flow lines were tracked, as in Fig. (10). The flow lines were in true path such as they turns in the return-bends.

Another type of validation was accomplished by comparing the shape of pressure contours of the present compressor with other certified results of centrifugal compressors. The compared cases are at different conditions as pressure ratios, mass flow rate, etc. Then, they did not need to put a legend of pressure values.

\section{SURGE SIMULATION}

Surge was numerically predicted by increasing the pressure ratio till flow 
oscillation starts. For the present research, the surge was predicted at $12 \mathrm{k} \mathrm{rpm}$ and mass flow rate $\dot{m}=0.009399 \mathrm{~kg} / \mathrm{s}$.

Likewise [Stein, 2000], the present surge was simulated in three regions. The first region is the inlet to the compressor. The second region is in the passage of the first impeller. The third region is the section along the centerline of the exit duct, Figs. (11) and (12). The arrows represent the velocity vectors and the arrow length scales the velocity magnitude.

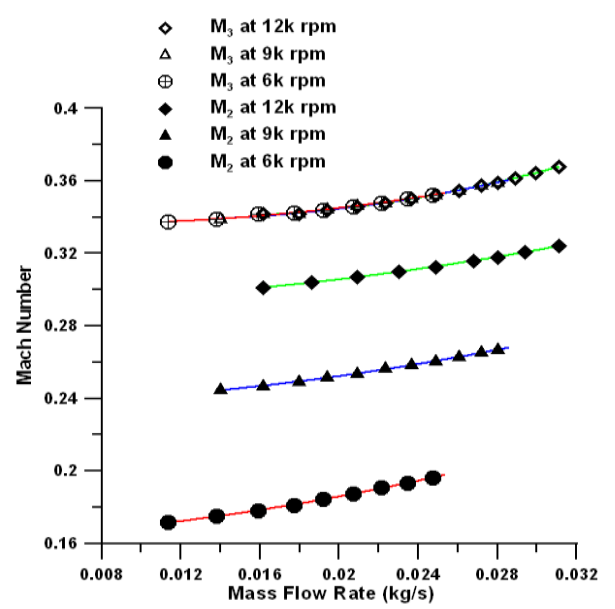

Fig. (9): Measured Mach Numbers at Compressor Inlet and Outlet vs. Mass Flow Rate for Different Compressor Speeds.

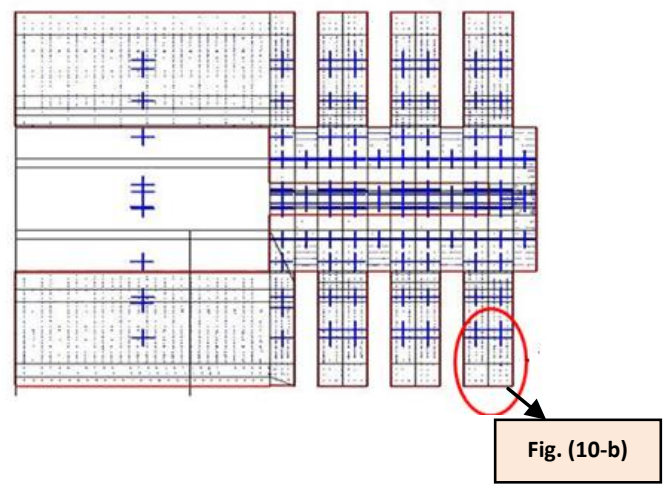

Fig. (10-a): Velocity Vectors in the return bend of Present Compressor.

\subsection{Compressor Inlet}

Fig. (13) shows the oscillation of the velocity vectors. These oscillations can be detected at compressor inlet by following the flow vectors with time steps. It is obviously seen that the velocity vectors move in the direction of partial reverse flow and then move back to the correct direction. The term partial reverse flow means that there are some velocity vectors but the overall flow moves in the correct direction. This partial reverse flow makes the flow oscillate.

At $t=0 \mathrm{sec}$, the numerical solution starts and the computational domain has the initial conditions. At $t=0.01 \mathrm{sec}$, the flow moves to the right and to the left to enter the impeller. At $t=0.02 \mathrm{sec}$, the velocity magnitude increases. At $t=0.03 \mathrm{se}$, the velocity magnitude decreases. By the same manner, the velocity magnitude continues to increase and decrease, which makes the flow oscillate. Since the net flow does not make a net reverse flow, this surge classified to mild surge.

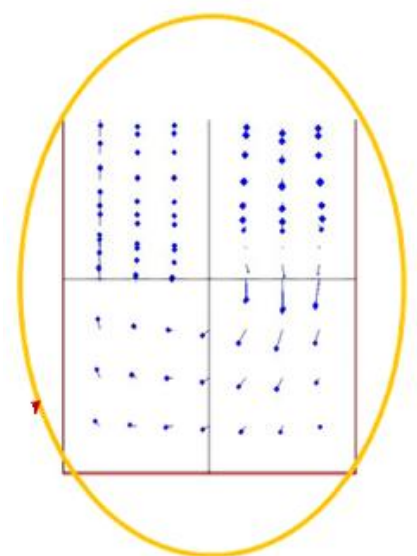

Fig. (10-b): Enlarged view from Fig. (10-a).

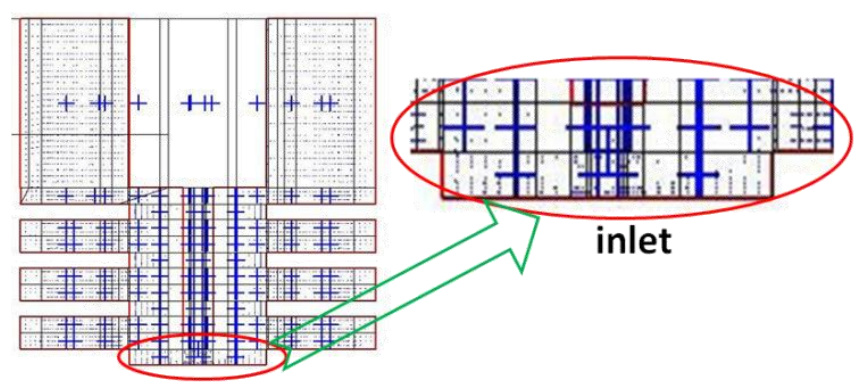

Fig. (11): Illustrative Cutaway View of First Region for Surge Study (inlet to the compressor). 


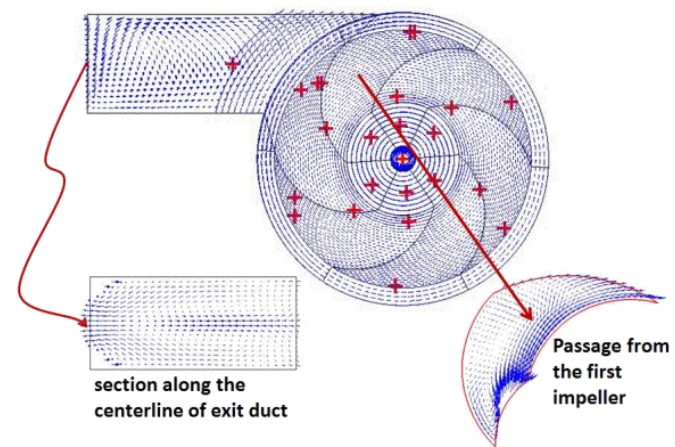

Fig. (12): Illustrative Cutaway View of Second and Third Regions of Simulated Surge.

\subsection{Impeller Passage}

Fig. (14) shows the surge simulation in a passage in the first impeller of the compressor. The impeller is backward, i.e., the impeller rotates in the $\mathrm{CCW}$ direction. Then, the right side of the passage is named as the positive pressure side of the blade. Also, the left side of the passage is named as the negative pressure side of the blade.

At $t=0.01 \mathrm{sec}$, the flow moves in a path adjacent to the positive pressure side in the passage. Full-span rotating stall appears next to the negative pressure side. The stall is a flow separation that forms a vortex or more. The rotating stall causes a blockage from one vortex or two vortices. This blockage narrows the flow in the right (in the positive pressure side).

At $t=0.02 \mathrm{sec}$, the separation blockage was decreases as the main vortex is divided into two vortices. The first one is big and goes up. The second one is small and goes down. The flow path increases since the stall blockage is decreased.

At $t=0.03 \mathrm{sec}$, the stall blockage was decreased also and then the flow path is increased. At $t=0.04 \mathrm{sec}$, the stall blockage increases rapidly and then the flow path decreases. At $t=0.05 \mathrm{sec}$, the stall blockage decreases and then the flow path increases. At $t=0.06 \mathrm{sec}$, flow path continues to increase as the stall blockage continues to decrease. The same matter continues for the reminder time steps.
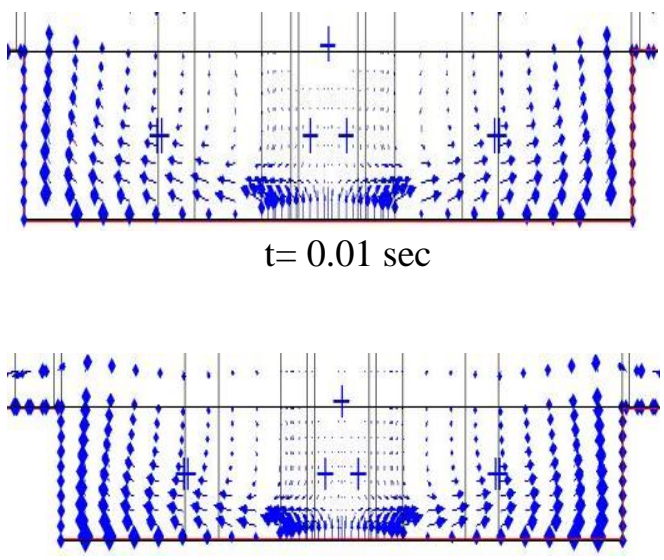

$\mathrm{t}=0.02 \mathrm{sec}$

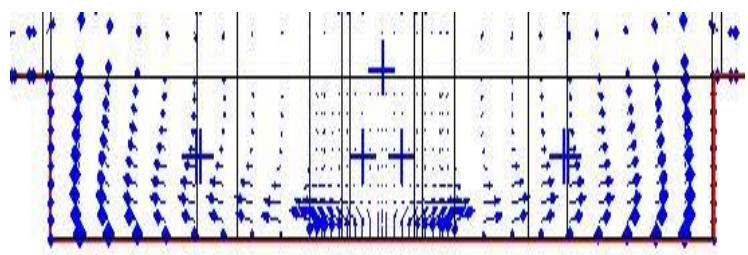

$\mathrm{t}=0.03 \mathrm{sec}$

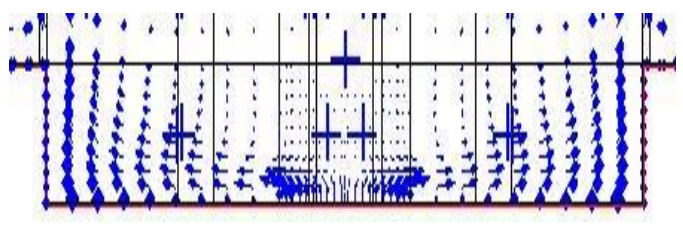

$\mathrm{t}=0.04 \mathrm{sec}$
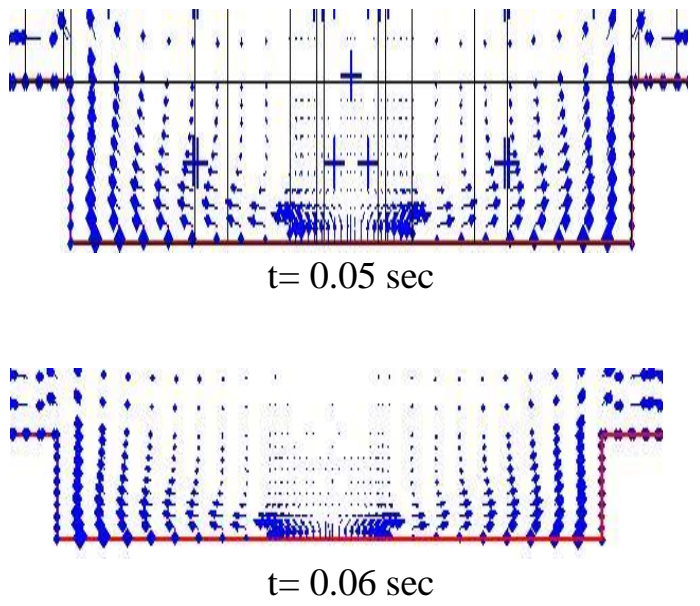

Fig. (13): Simulated Surge at Entrance, $(t=$ 0.01 sec to $t=0.06 \mathrm{sec}$ ), at $12,000 \mathrm{rpm}$ and $0.0093 \mathrm{~kg} / \mathrm{s}$. 


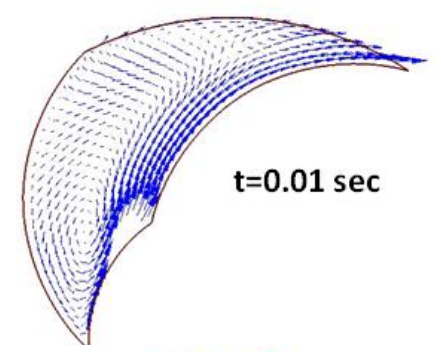

\subsection{Compressor Outlet Duct}

Surge is simulated in the outlet duct of the compressor, Fig. (15). This is a section along the centerline of the exit duct.

At $t=0.01 \mathrm{sec}$, the flow moves from the sides of the duct towards the middle. There is a partial reverse flow in the middle of the duct. Two small vortices are formed in the middle. Note that the partial reverse flow is small in comparison to the total flow and then the net flow has no reverse. Then, it is also mild surge and not deep surge since there is no net reverse flow.

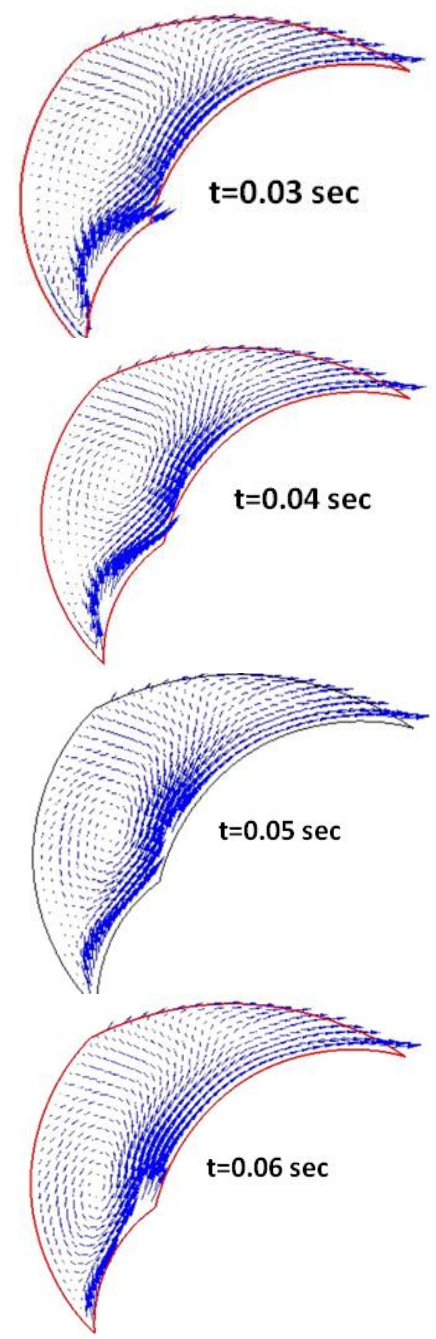

At $\mathrm{t}=0.02 \mathrm{sec}$, the two vortices decrease and then the partial reverse flow decreases and then the net flow increases. At $t=0.03$ $s e c$, the two vortices increase and the partial reverse flow increases and then the net flow decreases. By following the time steps, we can notice the flow fluctuations as the size of the partial reverse flow fluctuates.

\section{CONCLUSIONS}

The CFD-RC code was validated experimentally and numerically. It is capable numerically of solving the flow in the multi-stage centrifugal compressor. Also, the code was validated to simulate and predict the mild surge.

Computational results are very close to the experiment results. Thus, digital sensors are very efficient in measuring the flow in the centrifugal compressor.

Flow fluctuations at compressor exit are noticed where a mild surge occurs at 12,000 $\mathrm{rpm}$ and mass flow rate of $0.0093 \mathrm{~kg} / \mathrm{s}$. Surge was successfully predicted by unsteady computations.

In spite of the small pressure ratio of the present compressor, the study covers almost all features of such multi-stage centrifugal compressors.

Fig. (14): Simulated Surge in Passage of the First Impeller, $(t=0.01$ sec to $t=$ $0.06 \mathrm{sec}$ ), at 12,000 rpm and 0.0093 $\mathrm{kg} / \mathrm{s}$. 


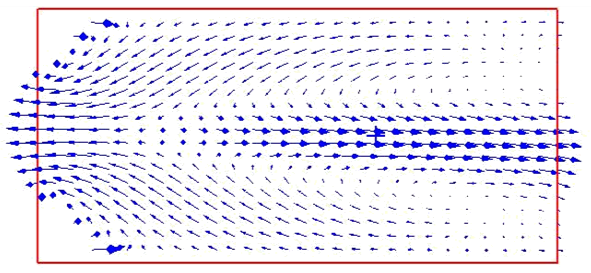

$\mathrm{t}=0.01 \mathrm{sec}$
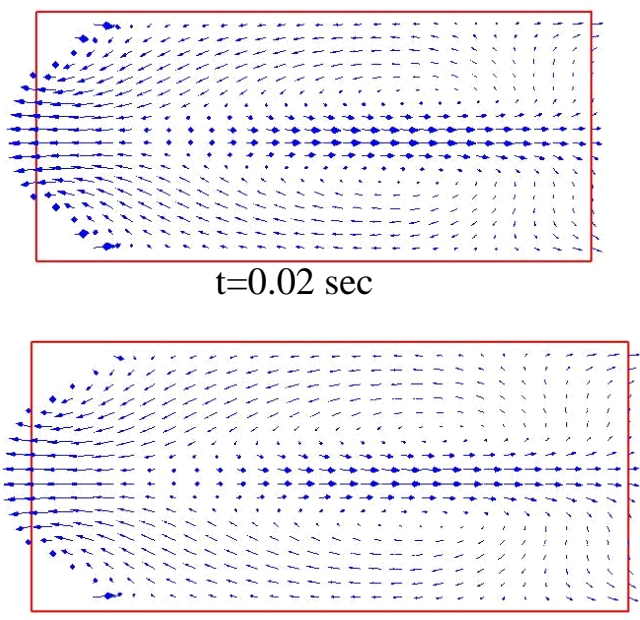

$\mathrm{t}=0.03 \mathrm{sec}$

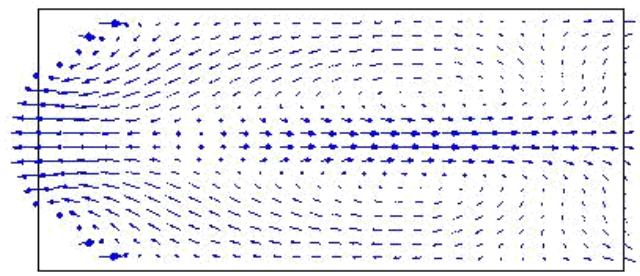

$\mathrm{t}=0.04 \mathrm{sec}$

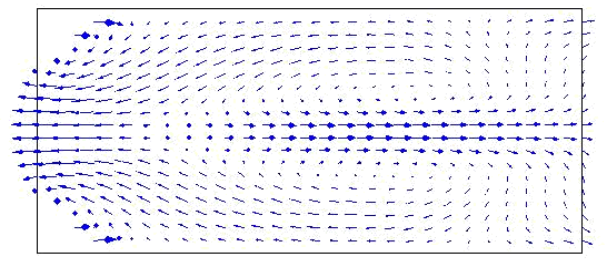

$\mathrm{t}=0.05 \mathrm{sec}$

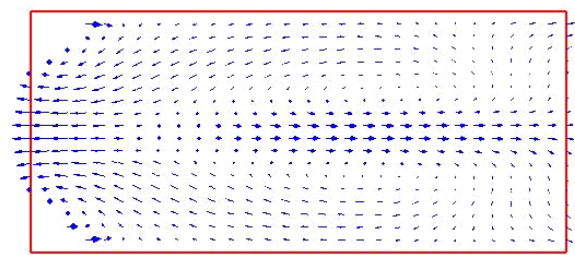

$\mathrm{t}=0.06 \mathrm{sec}$

Fig. (15): Simulated Surge in Outlet Duct $(t=0.01$ sec to $t=0.06$ sec $)$ at 12,000 rpm and $0.0093 \mathrm{~kg} / \mathrm{s}$.

\section{REFRENCES}

1. Cohen, H., Rogers, G. F. C., and Saravanamutto, H. I. H., "Gas Turbine Theory", Longman Group Limited, Fourth edition, 1996.

2. Ling, J., Wong, K. C., and Armfeild, S., "Numerical Investigation of a Small Gas Turbine Compressor", 16th Australian Fluid Mechanics Conference, Crown Plaza, Gold Coast, Australia, 2-7 Dec. 2007.

3. Mostafa, N. H., "Prediction of Surge and Rotating Stall in Compressor", Eighth International Conference in Fluid Dynamics and Propulsion (ICFDP8), Sharm El-Sheikh, Egypt, December, 2006.

4. Niazi, S., Stein, A., and Sankar, L. N., "Numerical Studies of Stall and Surge Alleviation in a High-speed Transonic Fan Rotor", AIAA, Paper 2000-0225, Jan., 2000.

5. Rangwala, A. S., "Turbo-machinery Dynamics; Design and Operation", McGraw-Hill, First Edition, USA, 2005.

6. Tang, J., Turunen-Saaresti, T., and Larjola, J., "Use of Partially Shrouded Impeller in a Small Centrifugal Compressor", J. Thermal Science, Vol. 17, No.1, pp. 21-27, Article ID: 1003-2169(2008)01-0021-07, Nov. 2008.

7. Tijl, P., "Modeling Simulation and Evaluation of a Centrifugal Compressor with Surge Avoidance Control", M.D. Thesis, Dynamic and Control Technology group, Mechanical Engineering Department, Technical University, Eindhoven, Netherlands, March 2004.

8. Xu, C., and Muller, M., "Development and Design of a Centrifugal Compressor Volute", Int. J. Rotating Machinery, Vol. 3, pp. 190-196, 2005.

9. Xinwei, S., Chuangung, G., Jun, X., and Chuang, G., "Centrifugal Compressor Blade Optimization Based on Uniform Design and Genetic Algorithm", Front. Energy Power Eng., DOI 10.1007/s11708-008-0083-5, CHINA, 2008.

10. Yutaka, O., Takashi, G., and Eisuke, O., "Effect of Tapered Diffuser Vane on the Flow Field and Noise of a Centrifugal Compressor", J. Thermal Science, Vol. 16, No.4, pp. 301-308, DIO: 10.1007/s11630-007-0301-1, 2007. 